TI 2014-012/V

Tinbergen Institute Discussion Paper

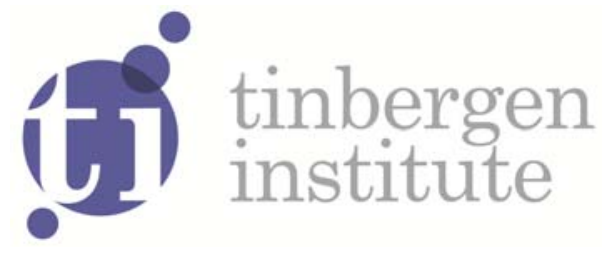

\title{
The Causal Links between Aid and Government Expenditures
}

Łukasz Marć 
Tinbergen Institute is the graduate school and research institute in economics of Erasmus University Rotterdam, the University of Amsterdam and VU University Amsterdam.

More TI discussion papers can be downloaded at http://www.tinbergen.nl

Tinbergen Institute has two locations:

Tinbergen Institute Amsterdam

Gustav Mahlerplein 117

1082 MS Amsterdam

The Netherlands

Tel.: +31(0)205251600

Tinbergen Institute Rotterdam

Burg. Oudlaan 50

3062 PA Rotterdam

The Netherlands

Tel.: +31(0)10 4088900

Fax: $+31(0) 104089031$

Duisenberg school of finance is a collaboration of the Dutch financial sector and universities, with the ambition to support innovative research and offer top quality academic education in core areas of finance.

DSF research papers can be downloaded at: http://www.dsf.nl/

Duisenberg school of finance

Gustav Mahlerplein 117

1082 MS Amsterdam

The Netherlands

Tel.: +31(0)20 5258579 


\title{
The Causal Links Between Aid and Government Expenditures
}

\author{
Łukasz Marć*
}

January 18, 2014

\begin{abstract}
The most recent literature on aid effectiveness finds a positive effect of aid on growth. To the extent that aid goes through the budget, this either reflects an aid-financed increase in government expenditures (quantity effect) or an improvement in the use of government resources as a result of donor involvement and lower taxes (quality effect). This study investigates the causal link between on-budget aid and government expenditures using a large cross-country panel data set for 53 countries and recent methodology to test Granger causality in heterogeneous panels. I find that in most countries donors do not change aid in response to changes in the level of government expenditures and that recipient governments react to aid by changing the way they use their own resources rather than by increasing spending. Contrary to conventional wisdom, there is little support for a quantity effect: aid Granger causes government expenditures in only eight countries. This suggests that aid substitutes for domestic government revenue and that aid is effective largely through the quality effect.
\end{abstract}

Keywords: foreign aid, government expenditures, Granger causality, fungibility JEL-code: E62, F35, H50, O23.

*Tinbergen Institute, VU University Amsterdam: lukasz.marc@vu.nl. I am especially grateful to Chris Elbers and Jan Willem Gunning for many useful comments and insights during numerous talks and to Eric Bartelsman, Bas van der Klaauw, Maarten Lindeboom, Remco Oostendorp, Lisette Swart, Melinda Vigh, Tymon Słoczyński and seminar participants at Tinbergen Institute, VU University, RGS Conference, Warsaw Economic Seminar and Izmir University for useful suggestions. The usual disclaimers apply. 


\section{Introduction}

A large body of literature on aid effectiveness has tried to assess the impact of aid on growth, poverty reduction and living standards in developing countries. ${ }^{1}$ Recently, the methodology and robustness of many of the best known aid effectiveness studies has been criticized (see, for example, Tarp 2006; Roodman 2007; Arndt et al. 2010). The most recent and methodologically stronger studies find a positive effect of aid on growth and poverty reduction (see Arndt et al. 2010, 2011; Alvi and Senbeta 2012; Juselius et al. 2013; Mekasha and Tarp 2013). Through what channels this impact is achieved is less clear (Arndt et al., 2011; Bourguignon and Sundberg, 2007). When aid is channeled through the budget it can either increase government expenditures, or substitute for other sources of government revenues. In the former case, it is likely that the positive impact of aid on growth reflects the aid-financed increase in government spending (quantity effect). However, aid can also substitute for domestic revenues. In that case, aid effectiveness reflects changes in the structure and quality of government spending or the impact of lower taxes (quality effect). To understand aid effectiveness it is therefore crucial to assess how on-budget aid influences government expenditures and vice versa.

The impact of aid on government expenditures is investigated in the fungibility literature and in fiscal response studies (for a review see Morrissey and McGillivray 2001, and Morrissey 2012). These literatures suffer from the same methodological weaknesses as the earlier aidgrowth regressions. A notable problem is the endogeneity of aid which has been ignored in many studies that investigate the impact of foreign aid on government expenditures. Marć (2012) summarizes three reasons to expect endogeneity discussed in the literature. Firstly, aid is received in packages designed for a few years and often the recipient decides on the timing of disbursement, which means that the level of government expenditures may be decided simultaneously with the level of aid in a given year (McGillivray and Morrissey, 2000). Secondly, donors may increase the amounts of aid in countries that fail to provide merit goods. Finally, as was pointed out by Pettersson (2007), some countries, possibly those with better institutions, may be allowed to treat part of their aid as fungible.

\footnotetext{
${ }^{1}$ The literature investigates the impact of total aid (both off-budget and on-budget) on development outcomes. However, this study investigates the importance of the government channel, hence it focuses only on on-budget aid. In this study aid and on-budget aid are used interchangeably.
} 
Since it is difficult to find good instruments for aid, I do not use an IV-approach to establish causality between government expenditures and on-budget aid. ${ }^{23}$ Instead I use Granger non-causality test for heterogeneous panel data as discussed by Hurlin and Venet (2001), and Hurlin and Dumitrescu (2012), and applied by Erdil and Yetkiner (2009) and Hood et al. (2008). With this method I can account for two types of heterogeneity (Hurlin and Venet, 2001): differences between countries in levels and slopes. The latter type of heterogeneity is the more crucial one, since if it is ignored, the general conclusion regarding the causality relationship in the sample may be biased.

I also investigate whether there are differences in causality patterns between countries. As a fraction of GDP the Least Developed Countries (LDCs) receive more than ten times as much aid as the Lower and Middle Income Countries (LMICs). ${ }^{4}$ Granger causality will not be detected if aid is fungible, that is if the government is able to react to the changes in aid by changing the way it uses its own resources. Since it is easier to make relatively small amounts of aid fungible, it is expected that on-budget aid will be Granger causing government expenditures among LDCs. ${ }^{5}$ The second reason for endogeneity, i.e. that donors may increase the amounts of aid in countries that fail to provide merit goods, also suggests that government expenditures should be Granger causing aid more often among the Least Developed Countries. ${ }^{6}$

The Granger causality test establishes the long term link between aid and government expenditures. The fungibility literature has focused on the short term impact of aid on government expenditures (Marć, 2012). To my knowledge, only Marć (2012) (at the aggregate level) and Van de Sijpe $(2010,2012)$ (at the sectoral level) have attempted to analyze also the long term impact, as does the present paper.

\footnotetext{
${ }^{2}$ Note that the Granger test can also give some indications regarding exogeneity. Granger causality is necessary (but not sufficient) for strong exogeneity. At the same time, it is neither necessary nor sufficient to establish weak exogeneity. However, as Maddala (2001) and Gujarati (2007) point out, the Granger test is considered to be a useful tool for description of time-series and panel data.

${ }^{3}$ Marć (2012) instruments aid and lagged government expenditures and uses GMM system estimator to investigate the impact of on-budget aid on government expenditures using similar dataset.

${ }^{4}$ All terms and concepts are understood as defined by the OECD and the World Bank and can be found in the glossary.

${ }^{5}$ It is not assumed that aid is fully fungible, but as argued bu Marć (2012), simple dynamic models suggest that an optimizing government would divide the increase in income to keep shares of private consumption and government spending constant.

${ }^{6}$ It is also rather probable that both links may not be detected for the Lower and Middle Income Countries due to the fact that aid constitutes only a very small share of the recipient countries' GDP in that group.
} 
To my knowledge, there is no cross-country study testing the Granger causality link between aid and government expenditures. On the country level, Osei et al. (2005) investigate the causal relation between aid and government expenditures in Ghana. They find that foreign aid is taken as given, that it is weakly exogenous and that it Granger causes government expenditures. Tax revenue, government spending and borrowing, on the other hand, adjust to an imbalance in the fiscal situation. In the related literature on aid effectiveness, Arvin and Barillas (2002) test the link between aid and the level of poverty, controlling for the level of democratization. They find substantial differences between countries at different levels of development and they comment that there is a real possibility in some cases that the disbursement of aid and poverty reduction are not linked positively. Roodman (2008) shows that growth is Granger causing aid.

The aim of this paper is to provide evidence on the causality between on-budget aid and government expenditures. Recent econometric techniques are used on the largest possible dataset. For most countries no causality is found, which means that governments are reacting to aid by changing the ways they use their own resources and that aid is fungible. Also, government expenditures are not Granger causing aid, which may mean that donors are not reacting immediately to changes in recipient countries and that the commitment packages have largely predetermined disbursement timing. The paper is organized as follows. Section 2 describes the methodology. Section 3 focuses on data and sample characteristics. Empirical results are presented and discussed in section 4 . The last section concludes.

\section{Methodology}

The idea of Granger causality as described in Granger $(1969,1980)$ is based on the principle that a cause cannot come after its effect. When variable $x$ is affecting a variable $y$, addition of the past values of the former variable should increase the precision of prediction of the latter variable (Lutkepohl, 2009). Kirchgassner and Wolters (2007) define it formally: for a weakly stationary time series (where the first and second moments are constant), an information set $I_{t}, \bar{x}_{t}$ being a set of all current and past values of $x$, and variance of the forecast error denoted by $\sigma^{2}$, Granger causality between $x$ and $y$ is defined as:

- Granger causality: $x$ is (simply) Granger causal to $y$ if and only if the application of 
an optimal linear prediction function leads to

$$
\sigma^{2}\left(y_{t+1} \mid I_{t}, \bar{x}_{t}\right)<\sigma^{2}\left(y_{t+1} \mid I_{t}\right)
$$

which means that inclusion of $x$ leads to better prediction of $y$.

- Instantaneous Granger causality: the application of an optimal linear prediction function leads to:

$$
\sigma^{2}\left(y_{t+1} \mid I_{t}, x_{t+1}\right)<\sigma^{2}\left(y_{t+1} \mid I_{t}\right)
$$

which means that future value of $y$ can be predicted better (involving smaller forecast errors) if the future value of $x$ is used in addition to the current and past values of $x$.

- Feedback: There is feedback between $x$ and $y$ if $x$ is causal to $y$ and $y$ is causal to $x$.

In applications, regression techniques and Wald statistics are used to test Granger causality. While Granger causality has mostly been tested in time series, during the last two decades there has been a substantial development of both methods and applications of Granger causality in the panel data setting, accounting for heterogeneity of panels (see Hurlin and Venet, 2001; Hurlin and Dumitrescu, 2012). Panel data have certain advantages over time series: both cross-sectional and time series information can be used to test causal relationships, which leads to a bigger sample, increases the number of degrees of freedom and reduces the collinearity among explanatory variables, thus improving the efficiency of Granger causality tests (Hurlin and Venet, 2001; Hurlin and Dumitrescu, 2012). It also increases flexibility in the modeling of cross-sectional units' behavior compared to time series (Hood et al., 2008).

The aim of the following subsection is to describe the methodology used to test the causal link between aid and government expenditures.

\subsection{Granger causality in the panel setting}

To test for Granger causality in a heterogeneous panel setting, I follow the methodology first proposed by Hurlin and Venet (2001) and applied, among others, by Hood et al. (2008), Erdil and Yetkiner (2009) and Arvin and Barillas (2002). The notation stays close to these 
papers. The following fixed effects model is estimated:

$$
y_{i, t}=\sum_{k=1}^{p} \alpha_{k} y_{i, t-k}+\sum_{k=k_{0}}^{p} \beta_{k}^{i} x_{i, t-k}+\gamma_{i}+u_{i, t}
$$

where $i$ denotes recipient, $k$ lag and $t$ year, both the autoregressive coefficients $\alpha_{k}$ and the regression coefficients $\beta_{k}^{i}$ are assumed to be constant over time for all $k$, and the parameters $\alpha_{k}$ are equal for all countries, ${ }^{7}$ whereas $\beta_{k}^{i}$ can be country specific. $\gamma^{i}$ is the fixed country effect, $u_{t}^{i}$ denotes an error term. I test both instantaneous causality (when $k_{0}=0$ ) and causality $\left(k_{0}=1\right)$. As Hurlin and Venet (2001) point out, the only difference in these procedures is formulation of the null and alternative hypothesis.

The first hypothesis to be tested is the Homogeneous Non Causality hypothesis (HNC) which answers the question whether all lagged values of $x$ are simultaneously not significant.

$$
H_{0}: \beta_{k}^{i}=\beta_{k}^{j}=0 \quad \forall i \in[1, N], \forall k \in\left[k_{0}, p\right], i \neq j
$$

$$
H_{1}: \beta_{k}^{i} \neq 0 \quad \exists(i, k)
$$

The following Wald statistic is calculated: ${ }^{8}$

$$
F_{H N C}=\frac{\left(S S R_{r 1}-S S R_{u}\right) /(N(p+a))}{S S R_{u} /[N T-N(1+(p+a))-(p+a)]}
$$

where $a=1$ for instantaneous causality (additional restriction) and $a=0$ for simple causality, $S S R_{u}$ denotes the sum of squared residuals of the unrestricted model described in equation 3 and $S S R_{r 1}$ is the sum of squared residuals of the model under the null hypothesis. Rejection of the null hypothesis means that there is at least one country for which $x$ is Granger causing $y$.

If $\mathrm{HNC}$ is rejected, I test whether causality is homogeneous for all recipients. The null hypothesis of the Homogeneous Causality hypothesis (HC) states that all $\beta_{k}^{i}$ are equal for

\footnotetext{
${ }^{7}$ These assumptions are needed to retain sufficient degrees of freedom.

${ }^{8}$ Since the panel used in this study is unbalanced, $T$ is the average number of periods in the sample.
} 
all countries. Formally:

$$
H_{0}: \beta_{k}^{i}=\beta_{k}^{j} \quad \forall i, j \in[1, N], \forall k \in\left[k_{0}, p\right]
$$

$$
H_{1}: \beta_{k}^{i} \neq \beta_{k}^{j} \quad \exists(i, j, k)
$$

Where $S S R_{r 2}$ denotes the sum of squared residuals under the null hypothesis. The Wald statistic is described by:

$$
F_{H C}=\frac{\left(S S R_{r 2}-S S R_{u}\right) /[(p+a)(N-1)]}{S S R_{u} /[N T-N(1+(p+a))-(p+a)]}
$$

When both homogeneous causality hypotheses are rejected, the process is heterogeneous. There may be a causal relation from $x$ to $y$ for a group of countries and no relation for the remaining. To estimate the Heterogeneous Non Causality hypothesis (HENC), a set of dummy variables for each panel member is created. These binary variables are multiplied by a vector of independent variables (either aid or government expenditures) to create a set of variables that assign the value of the independent variable for a particular country and zero for all other countries. ${ }^{9}$ That gives a set of 53 variables for each lag used, one per lag for each country and leads to 53 tests. As Hurlin and Venet (2001) point out, in that case the cross sectional information is only used to improve the specification of the model and the power of tests. The null and alternative hypotheses under HENC are:

$$
H_{0}: \beta_{k}^{i}=0 \quad \forall i \in[1, N], \forall k \in\left[k_{0}, p\right]
$$

$$
H_{1}: \beta_{k}^{i} \neq 0 \quad \forall i \in[1, N], \forall k \in\left[k_{0}, p\right]
$$

The following Wald statistic is used:

$$
F_{H E N C}=\frac{\left(S S R_{r 3}-S S R_{u}\right) /(p+a)}{S S R_{u} /[N T-N(1+2(p+a))+(p+a)]}
$$

\footnotetext{
${ }^{\mathrm{g}}$ Hood et al. (2008) describe this procedure in more detail.
} 
where $S S R_{r 3}$ is the sum of squared residuals under the null hypothesis. Using this specification, countries that contribute to the causality process can be detected.

A well known problem in the studies that use a lagged dependent variable is dynamic panel bias, pointed out by Nickell (1981). Roodman (2006) discusses the problem and suggests to use a fixed effects estimator, which should work well in long panels as the bias decreases with T. Judson and Owen (1999) confirm that in a Monte Carlo analysis. Therefore the fixed effects model is used.

\section{Data}

The initial sample consists of 91 countries classified as Least Developed Countries (LDCs) and Lower and Middle Income Countries (LMICs) in 2009 by the OECD. ${ }^{10}$ Data cover the period 1980-2009, and are (almost) complete starting from the 1990. The use of lagged variables increases the minimum length of time series required. Hurlin and Dumitrescu (2012) use the formula $T>5+2 p, p$ being the number of lags, to determine the number of time periods needed for estimation. ${ }^{11}$ For 3 lags the minimum number of periods equals 12, and 14 when instantaneous causality is tested. Therefore, all countries with less than 14 observations for government expenditures or aid are dropped, which decreases the number of analyzed countries from 91 to $53{ }^{12}$ and the number of observations to 1145 .

As noted before, this study focuses on the link of on-budget aid and government expenditures. The share of total government spending in GDP is taken from the International Monetary Fund's (IMF) World Economic Outlook (WEO). Data on aid disbursement are taken from the DAC2 OECD Table. Since precise data on on-budget and off-budget aid are not available, following Van de Sijpe (2012) technical cooperation (TC) is used as a proxy for off-budget aid. Technical cooperation includes payments to consultants, advisers and similar personnel in recipient countries and grants to citizens of recipient countries for education and training both at home and abroad, and its vast majority is not channeled through the budget. The remainder, i.e. total aid minus technical cooperation, gives a proxy for on-budget

\footnotetext{
${ }^{10} \mathrm{~A}$ more detailed description of the whole dataset, details on the data definitions, and a discussion of the quality and the precise sources can be found in Marć (2012).

${ }^{11}$ Hurlin and Dumitrescu (2012) point out that the second order moments of the Wald statistics exist only if that condition is satisfied.

${ }^{12}$ The list of the countries can be found in the Appendix.
} 
aid. Admittedly, it still contains off-budget elements.

Table 1 presents descriptive statistics. On average, on-budget aid accounts for $6.50 \%$ of recipient countries' GDP, $9.34 \%$ for the Least Developed Countries and 2.06\% for the Lower and Middle Income Countries. When the amounts are weighted by the size of economy, the average drops to $0.65 \%$, which reflects the fact that populous countries, like China and India, receive relatively small amounts of aid per capita. Also the discrepancy between LDCs and LMICs increases, the former group receives more than 10 times more aid expressed as a share of GDP. The share of government expenditures and the number of observations per country are stable across the groups.

Table 1: Share of government expenditures and on-budget aid in GDP (\%)

\begin{tabular}{lcccccc}
\hline \multicolumn{2}{c}{ Unweighted } & \multicolumn{2}{c}{ Weighted } & & \\
& Aid & Gov exp & Aid & Gov exp & Countries & Years \\
\hline Sample & 6.50 & 26.37 & 0.65 & 21.04 & 53 & 22.83 \\
LDCs & 9.34 & 26.01 & 4.61 & 20.17 & 32 & 23.12 \\
LMICs & 2.06 & 26.92 & 0.25 & 21.13 & 21 & 22.38 \\
\hline
\end{tabular}

\section{Results}

The following section presents results from the Granger causality tests. In the first part, tests for stationarity and the choice of lag length are discussed. Then, results for homogeneous and heterogeneous panel causality are presented and discussed.

\subsection{Non-stationarity and the choice of lag length}

Granger causality testing requires weak stationarity; the first and second moments should be constant. All variables used in the study are expressed in percentages, as a share of GDP, hence stationarity is likely. Both Im-Pesaran-Shin and Fisher tests ${ }^{13}$ reject the null hypothesis that all panels contain a unit root.

The choice of the lag length may affect the results of the Granger causality test. Odaki (1986) tests model selection criteria suggested by Akaike (1973), Schwarz (1978) and Hannan

\footnotetext{
${ }^{13}$ The only stationarity tests that allow unbalanced panels.
} 
and Quinn (1979) pointing out desirable asymptotic properties. However, these properties may not hold in small samples and the conclusions reached with these procedures are conditional on the criteria and information used (Urbain, 1989). Thornton and Batten (1985) show that the arbitrary lag-length specification can lead to misleading results. They suggest, that "the safest approach is to perform an extensive search of the lag space" (p. 177). Arvin and Barillas (2002) list the consequences of the wrong choice of the lag lengths. If too many lags are used, it is likely that the power of the test is reduced. Conversely, if too few lags are used, the results will be biased and residuals will be serially correlated. To determine the optimal length of the lags both AIC and BIC criteria are used. The following fixed effects model for the pooled dataset is estimated for both aid and government expenditures:

$$
y_{i, t}=\sum_{k=1}^{p} \alpha_{k} y_{i, t-k}+\gamma_{i}+\varepsilon_{i, t}
$$

The results of both tests suggest to use the model with the maximum number of lags available. Due to the length of time series (discussed in Section 3), which may lead to a low number of degrees of freedom, I limit the maximum number of lags analyzed to 3 .

\subsection{Granger causality tests}

After choosing the lag length, the procedures described in section 2.1 are followed. Equation 3 is estimated in order to test HNC and HC hypotheses (also for instantaneous causality). Table 2 presents the values of the Wald statistics for both hypotheses tested. The null of the Homogeneous Non Causality is rejected for both links and all groups at $1 \%$ level and the same applies to the Homogeneous Causality hypothesis. The rejections of HNC indicate that there exists a causal relation from aid to government expenditures and from government expenditures to aid, and since $\mathrm{HC}$ is also rejected, these causal links are not homogeneous.

In the next step, the heterogeneous causality hypothesis is tested for each country in the dataset, allowing for different $\beta_{k}^{i}$. The results are presented in Table 3 for both causality and instantaneous causality.

For the causality from on-budget aid to government expenditures, at a $5 \%$ significance level six Least Developed Countries contribute to the existence of the causal link: Equatorial 
Table 2: Homogeneous Non Causality Hypothesis (HNC) and Homogeneous Causality Hypothesis (HC) tests

\begin{tabular}{|c|c|c|c|c|c|}
\hline & \multicolumn{5}{|c|}{ Whole sample } \\
\hline \multirow{4}{*}{$\begin{array}{l}\text { Hypothesis } \\
\text { tested: } \\
\text { HNC }\end{array}$} & Causality & \multicolumn{2}{|c|}{ Granger causality } & \multicolumn{2}{|c|}{ Inst. Granger causality } \\
\hline & & $\mathrm{F}$ & P-val & $\mathrm{F}$ & P-val \\
\hline & Aid GC GovExp & 1.741 & 0.000 & 2.035 & 0.000 \\
\hline & GovExp GC Aid & 1.729 & 0.000 & 3.657 & 0.000 \\
\hline \multirow[t]{3}{*}{$\mathrm{HC}$} & Aid GC GovExp & 1.644 & 0.000 & 1.968 & 0.000 \\
\hline & GovExp GC Aid & 1.728 & 0.000 & 3.692 & 0.000 \\
\hline & \multicolumn{5}{|c|}{ Lower and Middle Income Countries (LMICs) } \\
\hline Hypothesis & Causality & \multicolumn{2}{|c|}{ Granger causality } & \multicolumn{2}{|c|}{ Inst. Granger causality } \\
\hline tested: & & $\mathrm{F}$ & $P$-val & $\mathrm{F}$ & P-val \\
\hline \multirow[t]{2}{*}{ HNC } & Aid GC GovExp & 1.393 & 0.003 & 1.500 & 0.000 \\
\hline & GovExp GC Aid & 2.008 & 0.000 & 1.745 & 0.000 \\
\hline \multirow[t]{3}{*}{$\mathrm{HC}$} & Aid GC GovExp & 1.323 & 0.009 & 1.454 & 0.000 \\
\hline & GovExp GC Aid & 1.848 & 0.000 & 1.631 & 0.000 \\
\hline & \multicolumn{5}{|c|}{ Least Developed Countries (LDCs) } \\
\hline \multirow{4}{*}{$\begin{array}{l}\text { Hypothesis } \\
\text { tested: } \\
\text { HNC }\end{array}$} & Causality & \multicolumn{2}{|c|}{ Granger causality } & \multicolumn{2}{|c|}{ Inst. Granger causality } \\
\hline & & $\mathrm{F}$ & $\mathrm{P}$-val & $\mathrm{F}$ & P-val \\
\hline & Aid GC GovExp & 1.895 & 0.000 & 2.308 & 0.000 \\
\hline & GovExp GC Aid & 1.762 & 0.000 & 4.025 & 0.000 \\
\hline \multirow[t]{2}{*}{$\mathrm{HC}$} & Aid GC GovExp & 1.759 & 0.000 & 2.210 & 0.000 \\
\hline & GovExp GC Aid & 1.711 & 0.000 & 4.014 & 0.000 \\
\hline
\end{tabular}

Guinea, Eritrea, Burundi, Sudan, Solomon Islands and Maldives. Additionally, at $10 \%$ level Uzbekistan and Comoros are also in that group. Among the Lower and Middle Income Countries, only for Mongolia and Iran aid is Granger causing government expenditures. Only for one country from LMICs, the Republic of Congo, government expenditures are Granger causing aid, whereas it is the case for seven countries from the group of LDCs (and for one more at $10 \%$ level). All in all, for three countries the causality link is bidirectional: Equatorial Guinea, Burundi and Eritrea.

There are 21 Lower and Middle Income Countries in the sample and 32 Least Developed Countries. Out of the 13 countries for which any causal relation has been found at the $5 \%$ level, only Mongolia, Iran and the Republic of Congo are from the group of LMICs (14\% of the group), the remaining 10 are Least Developed Countries (and account for 31\% of that group). That is in line with expectations described in the introduction. Since aid accounts for only a small share of GDP (and consequently government expenditures) among Lower and Middle Income Countries, the response of the level of government expenditures to the changes in aid is smaller (or not detectable). Also, LMICs have better access to credit 
Table 3: Granger causality and instantaneous Granger causality

\begin{tabular}{|c|c|c|c|}
\hline \multirow{2}{*}{\multicolumn{2}{|c|}{$\begin{array}{c}\text { LDCs } \\
\text { Direction }\end{array}$}} & \multicolumn{2}{|r|}{ LMICs } \\
\hline & & Country & Direction \\
\hline Equatorial Guinea & Bidirectional (also inst.) & Mongolia & Aid causing GovExp (also inst.) \\
\hline Eritrea & Bidirectional (also inst.) & Iran & Aid causing GovExp (only inst.) * \\
\hline Burundi & Bidirectional (also inst.) & Moldova & Inconclusive \\
\hline Sudan & Aid causing GovExp (also inst.) & Morocco & Inconclusive \\
\hline Uzbekistan & Inconclusive $*, * *$ & Algeria & Inconclusive \\
\hline Solomon Islands & Aid causing GovExp (only inst.)* & Swaziland & Inconclusive \\
\hline Maldives & Aid causing GovExp (only inst.)* & Rep. of Congo & GovExp causing Aid (only inst.) $\dagger$ \\
\hline Lesotho & Inconclusive & China & Inconclusive \\
\hline Chad & Inconclusive & Ecuador & Inconclusive \\
\hline Comoros & Inconclusive $* *$ & El Salvador & Inconclusive \\
\hline Djibouti & Inconclusive & Thailand & Inconclusive \\
\hline Bhutan & Inconclusive & Jordan & Inconclusive \\
\hline Ghana & Inconclusive & Colombia & Inconclusive \\
\hline Papua New Guinea & Inconclusive & Sri Lanka & Inconclusive \\
\hline Dem. Rep. of Congo & GovExp causing Aid (also inst.) & Namibia & Inconclusive \\
\hline Mozambique & GovExp causing Aid (also inst.) & Syria & Inconclusive \\
\hline Benin & Inconclusive & Bolivia & Inconclusive \\
\hline Rwanda & GovExp causing Aid (also inst.) & Paraguay & Inconclusive \\
\hline Guinea & Inconclusive & Tunisia & Inconclusive \\
\hline Central African Rep. & Inconclusive & Philippines & Inconclusive \\
\hline Cambodia & Inconclusive & India & Inconclusive \\
\hline Burkina Faso & Inconclusive & & \\
\hline Tanzania & Inconclusive & & \\
\hline Yemen & Inconclusive & & \\
\hline Togo & Inconclusive & & \\
\hline Ethiopia & Inconclusive & & \\
\hline Vanuatu & Inconclusive $\dagger \dagger$ & & \\
\hline Madagascar & GovExp causing Aid (only inst.) & & \\
\hline Pakistan & Inconclusive & & \\
\hline Kenya & Inconclusive & & \\
\hline Bangladesh & Inconclusive & & \\
\hline Niger & Inconclusive & & \\
\hline $\begin{array}{l}\text { Countries are sorted } \\
\text { aid to government ex } \\
* \text { at } 10 \% \text { level, aid is } \\
* * \text { at } 10 \% \text { level, aid } \\
\dagger \text { at } 10 \% \text { level, also }\end{array}$ & $\begin{array}{l}\text { ording to the p-value of the test } \\
\text { iditures. } 5 \% \text { level is assumed for } \\
\text { anger causing government exper } \\
\text { stantaneously Granger causing }\end{array}$ & $\begin{array}{l}\text { Granger caus } \\
\text { erference. } \\
\text { Ires. } \\
\text { rnment expe }\end{array}$ & $\begin{array}{l}\text { y from } \\
\text { ures. }\end{array}$ \\
\hline
\end{tabular}

markets and foreign aid may crowd out credit, hence inconclusive answer is more likely than in more credit-constrained LDCs.

As a robustness check, I include five controls in equation 3: annual GDP growth (in \%), lagged annual inflation rate, lagged agricultural value added as a share of GDP, lagged sum of imports and exports of goods and services as share of GDP, and lagged infant mortality rate per 1000 births. These regressors has been used in other studies to explain the size of 
government expenditures or inflow of aid. ${ }^{14}$ At a $10 \%$ level, the causality link stays bidirectional for Equatorial Guinea and Eritrea. Aid is still found to Granger cause government expenditures for Mongolia, Sudan, Uzbekistan, Solomon Islands and Iran, and additionally for Rwanda, while for Burundi and Maldives inconclusive results are found. For all other countries, results stay inconclusive. For the causality going from government expenditures to aid, compared to the main results from table 3 conclusions change for two countries: Granger causality is found for Mongolia, while an inconclusive result for the Republic of Congo.

In summary, for the majority of countries, aid is neither Granger causing government expenditures, nor the other way around. That means that past values of aid (government expenditures) are not helpful in predicting the current level of government expenditures (aid). It further suggests two things. Firstly, the government reacts to on-budget aid by changing the way it uses its own resources, which means that aid is fungible. The intuition behind this result is that when aid flows increase, the government reduces its own revenues (or the budget deficit) to keep the level of total government expenditures constant and aid is substituting government expenditures. Secondly, aid does not respond to changes in government expenditures since past levels of government expenditures are not predictive for current values of aid. That may suggest that the disbursement schedule may be predetermined and that recipients do not have discretionary power to affect the timing of disbursement. That may also mean that donors do not react to the budgetary situation in the recipient country.

As noted before, recent studies on aid effectiveness show that aid has a positive impact on development outcomes, see for example: Arndt et al. (2010, 2011); Alvi and Senbeta (2012); Juselius et al. (2013); Mekasha and Tarp (2013). At the same time, on the aggregate level on-budget aid is highly fungible and around $50 \%$ substitutes government revenues in the long run (Marć, 2012) and, as this study shows, for the majority of countries on-budget aid is not Granger causing government expenditures. These results suggest that it is quite plausible that the main impact of aid is not going through increased government spending. Other channels may be also important. On-budget aid may have an impact on the structure and

\footnotetext{
${ }^{14}$ Marć (2012) discussed the choice of these controls. Agricultural value added controls for spending in agriculture and serves as a proxy for the level of development. Infant mortality is a proxy for expenditures in social security and health sectors. The growth rate is used a proxy for shocks to expenditures: if recipients can decide on the the timing of aid disbursement, the government can respond to shocks to expenditures by changing the amount of foreign aid. Openness of economy and inflation rate has been found to explain variation in the size of government expenditures in the literature.
} 
quality of the entire budget, pushing for expenditures that are important for development. It may also happen that thanks to on-budget aid the tax burden is lower, and hence returns to private investment and resources available for private consumption are higher. What is more, it is also possible that non-fungible off-budget aid is driving the positive impact on growth and poverty reduction.

\section{Conclusions}

This study investigates the causal link between on-budget aid and government expenditures. A Granger causality test that allows for cross-sectional heterogeneity of recipients and heterogeneity in coefficients' slopes is applied to data for 53 developing countries for the period 1990-2009. For most countries, I find no evidence of causality. For only 6 out of 32 Least Developed Countries on-budget aid Granger causes government expenditures while for 7 countries government expenditures Granger cause aid. The two groups overlap: for 3 countries causality is bidirectional. For the Lower and Middle Income Countries, aid Granger causes government expenditures in only 2 out of 21 countries, and in a single country the causality is in the opposite direction while no bidirectional causality was found. These results are plausible as it is easier to make aid fungible in richer countries since it accounts for a small part of government expenditures. However, it is also quite likely that due to the relatively small amounts of aid causality may not be detectable for LMICs.

These findings suggest that (i) contrary to conventional wisdom on-budget aid does not increase expenditures (fungibility); recipient governments adjust other sources of government revenues e.g. taxation, (ii) donors do not react to the changes in government expenditures, presumably because there is little scope for changing the timing of disbursement. My findings indicate that the positive impact of aid on development outcomes presented in recent studies does not reflect the financing role of on-budget aid (the quantity effect) but changes in the use of government resources and reduced domestic resource mobilization (the quality effect) or the effectiveness of off-budget aid. 


\section{Appendix}

Lower and Middle Income Countries: Algeria, Bolivia, China, Colombia, Republic of Congo, Ecuador, El Salvador, India, Iran, Jordan, Moldova, Mongolia, Morocco, Namibia, Paraguay, Philippines, Sri Lanka, Swaziland, Syria, Thailand, Tunisia.

Least Developed Countries: Bangladesh, Benin, Bhutan, Burkina Faso, Burundi, Cambodia, Central African Republic, Chad, Comoros, Democratic Republic of Congo, Djibouti, Equatorial Guinea, Eritrea, Ethiopia, Ghana, Guinea, Kenya, Lesotho, Madagascar, Maldives, Mozambique, Niger, Pakistan, Papua New Guinea, Rwanda, Solomon Islands, Sudan, Tanzania, Togo, Uzbekistan, Vanuatu, Yemen.

\section{References}

Akaike, H. (1973). Information Theory and an Extension of the Maximum Likelihood Principle . In: B.N. Petrov and F.Csaki, eds. Second International Symposium of Information Theory, pages 267-281.

Alvi, E. and Senbeta, A. (2012). Does Foreign Aid Reduce Poverty? Journal of International Development, 24(8):955-976.

Arndt, C., Jones, S., and Tarp, F. (2010). Aid, Growth, and Development: Have We Come Full Circle? Journal of Globalization and Development, 1(2):5.

Arndt, C., Jones, S., and Tarp, F. (2011). Aid effectiveness: Opening the Black Box. Working Papers UNU-WIDER Working Paper, World Institute for Development Economic Research (UNU-WIDER).

Arvin, B. M. and Barillas, F. (2002). Foreign Aid, Poverty Reduction, and Democracy. Applied Economics, 34(17):2151-2156.

Bourguignon, F. and Sundberg, M. (2007). Aid Effectiveness - Opening the Black Box. American Economic Review Papers And Proceedings, 97(2):316-321.

Erdil, E. and Yetkiner, I. H. (2009). The Granger-causality Between Health Care Expenditure and Output: a Panel Data Approach. Applied Economics, 41(4):511-518. 
Granger, C. W. J. (1969). Investigating Causal Relations by Econometric Models and CrossSpectral Methods. Econometrica, 37(3):424-38.

Granger, C. W. J. (1980). Testing for Causality: A Personal Viewpoint. Journal of Economic Dynamics and Control, 2(1):329-352.

Gujarati, D. (2007). Basic Econometrics With Data Cd (Sie). McGraw-Hill Education (India) Pvt Limited.

Hannan, E. J. and Quinn, B. G. (1979). The Determination of the Order of an Autoregression. Journal of the Royal Statistical Society. Series B (Methodological), 41(2):pp. 190-195.

Hood, M. I., Kidd, Q., and Morris, I. L. (2008). Two Sides of the Same Coin? Employing Granger Causality Tests in a Time Series Cross-Section Framework. Political Analysis, $16(3): 324-344$.

Hurlin, C. and Dumitrescu, E. (2012). Testing for Granger Non-causality in Heterogeneous Panels. Working Papers halshs-00224434, HAL.

Hurlin, C. and Venet, B. (2001). Granger Causality Tests in Panel Data Models with Fixed Coefficients. mimeo, University Paris IX.

Judson, R. A. and Owen, A. L. (1999). Estimating Dynamic Panel Data Models: a Guide for Macroeconomists. Economics Letters, 65(1):9-15.

Juselius, K., Møller, N. F., and Tarp, F. (2013). The Long-Run Impact of Foreign Aid in 36 African Countries: Insights from Multivariate Time Series Analysis*. Oxford Bulletin of Economics and Statistics, Forthcoming.

Kirchgassner, G. and Wolters, J. (2007). Introduction To Modern Time Series Analysis. Springer.

Lutkepohl, H. (2009). New Introduction To Multiple Time Series Analysis. Springer.

Maddala, G. (2001). Introduction to Econometrics. Wiley. 
Marć, Ł. (2012). New Evidence on Fungibility at the Aggregate Level. Tinbergen Institute Discussion Papers, 12-083/2.

McGillivray, M. and Morrissey, O. (2000). Aid Fungibility in Assessing Aid: Red Herring or True Concern? Journal of International Development, 12(3):413-428.

Mekasha, T. J. and Tarp, F. (2013). Aid and Growth What Meta-Analysis Reveals. The Journal of Development Studies, 49(4):564-583.

Morrissey, O. (2012). Aid and Government Fiscal Behaviour: What Does the Evidence Say? Working Paper Series, World Institute for Development Economic Research (UNUWIDER).

Morrissey, O. and McGillivray, M. (2001). Fiscal Effects of Aid. Working Papers Discussion Paper No. 2001/61, World Institute for Development Economic Research (UNU-WIDER).

Nickell, S. J. (1981). Biases in Dynamic Models with Fixed Effects. Econometrica, 49(6):1417-26.

Odaki, M. (1986). Tests of Granger Causality by the Selection of the Orders of a Bivariate Autoregressive Model. Economics Letters, 22(2,3):223-227.

Osei, R., Morrissey, O., and Lloyd, T. (2005). The Fiscal Effects of Aid in Ghana. Working Papers RP2005/61, World Institute for Development Economic Research (UNU-WIDER).

Pettersson, J. (2007). Foreign Sectoral aid Fungibility, Growth and Poverty Reduction. Journal of International Development, 19(8):1074-1098.

Roodman, D. (2006). How to Do xtabond2. North American Stata Users' Group Meetings 2006 8, Stata Users Group.

Roodman, D. (2007). The Anarchy of Numbers: Aid, Development, and Cross-Country Empirics. World Bank Economic Review, 21(2):255-277.

Roodman, D. (2008). Through the Looking-Glass, and What OLS Found There: On Growth, Foreign Aid, and Reverse Causality. Working Papers 137, Center for Global Development. 
Schwarz, G. (1978). Estimating the Dimension of a Model. The Annals of Statistics, 6(2):pp. 461-464.

Tarp, F. (2006). Aid and Development. MPRA Paper 13171, University Library of Munich, Germany.

Thornton, D. L. and Batten, D. S. (1985). Lag-Length Selection and Tests of Granger Causality between Money and Income. Journal of Money, Credit and Banking, 17(2):16478.

Urbain, J. P. (1989). Model Selection Criteria and Granger Causality Tests : An Empirical Note. Economics Letters, 29(4):317-320.

Van de Sijpe, N. (2010). Is Foreign Aid Fungible? Evidence from the Education and Health Sectors. Working Papers of Faculty of Economics and Business Administration, Ghent University, Belgium 10/688, Ghent University, Faculty of Economics and Business Administration.

Van de Sijpe, N. (2012). Is Foreign Aid Fungible? Evidence from the Education and Health Sectors. The World Bank Economic Review. 